\title{
Developing the Participatory Education Program for Dengue Prevention and Control in the Primary School, Southern Region, Thailand
}

\author{
Charuai Suwanbamrung ${ }^{*}$, Kiatgumjorn Kusol1, Kanokwan Tantraseneerate ${ }^{1}$, \\ Somjit Promsupa ${ }^{2}$, Teera Doungsin ${ }^{3}$, Supapron Thongchan ${ }^{4}$, Monlana Laupsa ${ }^{3}$ \\ ${ }^{1}$ School of Nursing, Walailak University, Nakhon Si Thammarat Province, Thailand \\ ${ }^{2}$ Health Promotion Hospital of Kamphaeng Sao Sub-District, Nakhon Si Thammarat Province, Thailand \\ ${ }^{3}$ Local Administrative Organization of Kamphaeng Sao Sub-District, Nakhon Si Thammarat Province, Thailand \\ ${ }^{4}$ Center for Computer Services, Walailak University, Nakhon Si Thammarat Province, Thailand \\ Email: 'Scharuai@wu.ac.th
}

Received 14 December 2014; accepted 10 October 2015; published 13 October 2015

Copyright (C) 2015 by authors and Scientific Research Publishing Inc.

This work is licensed under the Creative Commons Attribution International License (CC BY). http://creativecommons.org/licenses/by/4.0/

(c) (7) Open Access

\section{Abstract}

Dengue disease had been the significant health problem of the primary school in southern Thailand. The objective was to develop the participatory program for dengue prevention and control in five primary schools. Participatory action research (PAR) was applied in five steps: 1) preparation, 2) assessment, 3) education program development, 4) implementation and 5) evaluation. Data collection used quantitative and qualitative methods in five primary schools in Southern, Thailand. Descriptive statistics and Chi-square $\left(\chi^{2}\right)$ test were used to compare between pre- and post-intervention. Larval Indices were obtained from ratio analysis. The results showed the participatory program consisted of nine important activities for all stakeholders involving dengue problem. Health teacher's activities and student's activities were eight activities consisted of knowledge training, dengue manual, Computer Assisted Instructor (CAI), test, dengue data, larval indices survey, fish bank, and herbal garden. The seven activities of health provider were knowledge training, dengue manual, CAI, testing, dengue data, larval indices survey, and larval indices program. Three activities for students' parents included dengue manual, dengue data, and larval indices survey. The 290 students were participating activities in education program and increasing basic knowledge of dengue prevention and control. Comparing the number of correct answers, $>\mathbf{8 0} \%$ of students between pre- and post-intervention were found to increase basic knowledge from five correct answers to ten, and of these six items were significantly different $(P<0.001)$. The two

\footnotetext{
*Corresponding author.
}

How to cite this paper: Suwanbamrung, C., Kusol, K., Tantraseneerate, K., Promsupa, S., Doungsin, T., Thongchan, S. and Laupsa, M. (2015) Developing the Participatory Education Program for Dengue Prevention and Control in the Primary School, Southern Region, Thailand. Health, 7, 1255-1267. http://dx.doi.org/10.4236/health.2015.710140 
primary schools were continuing non-positive containers (Container Index: $\mathrm{CI}=\mathbf{0}$ ), but the total larval indices (Breteau Index: BI, House Index: HI, and Container Index: CI) of five primary schools showed high levels both pre- and post-intervention in primary schools; whereas, the students' households showed high level of BI, HI and CI both pre- and post-intervention $(754,77$, and 35 to 616,81 , and 32). Conclusion: The program was needed to continue in primary school and participate from health teacher, health provider, and students' parents in order to be of great benefit for students.

\section{Keywords}

\section{Education Program, Primary School, Participatory, Dengue Prevention and Control}

\section{Introduction}

Worldwide, an estimated 2.5 billion people are at risk of infection, approximately 975 million of whom live in tropical and sub-tropical countries [1]. In Thailand, dengue has been an important public health problem for the past fifty years [2]. Southern Thailand has a dengue problem due to high morbidity rate and high larval indices. It has seen higher dengue incidence than other areas of Thailand, possibly due to factors such as a greater number of rainy days, more rainfall, higher relative humidity, and warmer temperatures [3]. The significantly high risk factors relating to dengue are due to the population's behavior which focuses on vector breeding at peridomestic and intradomestic areas. In particular, where there are the most breeding sites such as outdoor water containers, water supply, waste disposal, and dengue knowledge associated with larval breeding and dengue illness [4]-[6]. Vulnerable populations who lack knowledge, have low incomes, irregular water service, overcrowded housing [6], and local rural community in which lakes serve as the water supply all enhance their risk of dengue [7]. Moreover, all risk factors are closely related to management based on multi-intervention in the community [4]. The larval indices are a classical index of dengue which decreases when using an education program [8] [9].

Education programs show children and their parents the need for effective dengue knowledge to change their behavior to prevent and control dengue and increase their parents' dengue knowledge through directed messages [10]. An attitude survey of dengue prevention and control in nine primary schools in Thailand showed that an education program for all stakeholders was successful [11]. However, the schools need a clear model of activities and an integration program suitable for a primary school. The results of the study were in contrast to the qualitative study of a community and school-based education program which showed that there were many factors for an effective program of children's knowledge such as equipment, content of dengue, teacher's commitment, and budget [12]. Another study of an education program for primary students in grades 7, 8, and 9 consisted of training for one week in eight weeks, health education to prevent dengue transmission [13], and student participation within the school context enhancing implementation of dengue prevention and control in student group activities [14]. Many reviews have concluded that school-based education and activities are an important compliment to increase students' knowledge of and participation in controlling dengue [12] [15]-[17]. Moreover, a study on basic knowledge and activities of children in Islamic religious schools which opened only on a Saturday and Sunday showed that activities relating to dengue could be tailored based on the age and development of all children [14].

Kamphaeng Sao sub-district is a rural and semi-rural area of Nakhon Si Thammarat province in southern Thailand. The sub-district has been conducting dengue prevention and control since 2009. Although the community has been the subject of several studies for successful solution of the dengue problem such as training the village health volunteers, high school-based and activities program, community network for prevention and control [14] [18], the primary schools in the sub-district clearly lack an intervention program for dengue prevention and control. There have been no reports of death due to dengue in the past two years (year 2010 to 2011), [18]. In April 2012, the first child with dengue was reported and might be used to predict a dengue outbreak because dengue could be transmitted from humans, mosquitos, and environment. However, the morbidity rate ( 5 per 100,000 populations) was lower than the Thai Ministry of Public Health's disease standard ( $<20$ per 100,000 populations). The results of the dengue study showed that continuing community activities were needed to be 
employed in the community [19]. The morbidity rate showed a high risk of a dengue epidemic in the community because almost all the student's households were in Kamphaeng Sao sub-district.

We know that dengue is a problem related to risk from the school and students' households which must be solved by all stakeholders in the community. Thus, this study aims to develop and evaluate an education program for dengue prevention and control in a primary school, in a sub-district in southern Thailand. The study focuses on the process of participatory development of all relevant students and evaluates the basic dengue knowledge of students and their parents, larval indices of five schools.

\section{Materials and Methods}

The study was approved by the authors' institutional reviews committee, the Ethical Review Committee for Research Subjects, the Health Science Group, Walailak University, Thailand, protocol number 12/011. The researcher provided the objectives of the study to five primary schools, the local administrative organization and obtained informed consent (written) from the students' parents for collecting data and participation of the student's household survey.

\subsection{Study Area and Participants}

The study took place from April 2012 to March 2013 for assessment situation [20], and participatory plan, implementation, and evaluation in the study continues from April to September, 2012. The study was conducted in five primary schools in Kamphaeng Sao, Nakhon Si Thammarat, Southern region, Thailand.

\subsection{Methods of the Development Step}

A participatory action research (PAR) plan was applied for meeting the students, discussion with the teacher group, answering a basic knowledge questionnaire on dengue, and surveying the school environment. There were five steps: 1) preparation, 2) assessment, 3) education program development, 4) implementation, and 5) evaluation.

\subsubsection{Preparation Step}

The exploration step was selected in order to better understand the diversity of the dengue problem among the students. This step consisted of a situation assessment based on the student's basic knowledge assessment, and primary school survey.

Dengue's basic knowledge testing, the student's basic knowledge of dengue was assessed by the researcher team in a meeting of students in each primary school. The questionnaires were developed and tested by the researcher. The format of the self-report of basic knowledge consisted of two parts: Part I: General characteristics, Part II: children's basic knowledge. The content validity by three experts in dengue prevention and control and reliability was tested with 30 students and analyzed by Cronbach's alpha 0.83 . The survey was 15 minutes long and consisted of 15 questions on dengue knowledge divided into three categories for each question; yes, no, and unknown. Dengue' basic knowledge questions were distributed into topics on the cause of dengue, major signs of dengue, mosquito-bite prevention, dangers of dengue, mosquito life cycle, and methods for mosquito elimination. The responsible parties for dengue prevention and control program in the five primary schools and the community were all stakeholders in the community [21]-[23]. Then, for the study, all students of primary education level 4, 5, and 6 were selected for participating in a self-report, school and their household survey. The three primary education levels were studying a health education course following a standard Thai primary school course.

The dengue problem solution methods from students meeting, they fostered a relaxed climate for the meeting, the meeting used 10 - 15 minutes per meeting. The short meeting took place after taking the questionnaires of dengue's basic knowledge. The students were asked by the researcher about dengue prevention methods, and then discussed and showed their ideas on paper. However, the teacher in each primary school helped the research team for conducting on the meeting. The students' suggestions were analyzed and grouped by category.

Primary school survey, Standard larval index surveys [9] as epidemiological indicators of dengue transmission should be viewed with caution. The three traditional larval indices were: the House Index (HI)—-the percentage of houses infested with larvae and/or pupae; the Container Index (CI)—-the percentage of water-holding 
containers infested with larvae and/or pupae; and the Breteau Index (BI) — the number of positive containers per 100 houses inspected [23] [24].

\subsubsection{Assessment Step}

Primary school survey, the health education teacher of each primary school and representatives of students surveyed the school's environment and buildings such as: drinking water containers; used water containers; water containers in the bathroom and toilet; cupboard saucers in the cafeteria; vases; plants-related containers; and discarded containers in and surrounding the building in school's area. The students were shown the survey format, information sheet and the informed consent form to their parents, and then cooperated to survey the mosquito breeding sites. Students sent the results of their survey to the assigned classroom teacher, and then the research team from the five primary schools.

Results of assessment step presented 290 students (primary education level 4, 5, and 6) from five primary schools in the community. The results of this step were high risk of dengue problem because highly level of dengue indices (BI, HI, and CI) in primary schools (200, 60, and 8), and their households (754, 77, and 35) [20]. There were five questions for which more than $80 \%$ of students answered correctly such as: question number 2 ; 9; 10; 14 and 15 (82.5\%; 84.3\%; 89.2\%; 95.8\%; and 82.4\%, respectively). The percentages of incorrect and unknown items were important issues for improving the student's dengue knowledge. The five meetings among the teachers, a representative of the Local Administrative Organization, a health provider from the community's hospital, and the principle researcher took place in each primary school. The conclusion of the results after discussion with the teacher showed three themes such as: "Dengue education program in the previous time did not show obvious methods"; "Schools will provide basic dengue knowledge"; and "New methods of dengue prevention and control must involve schools and the student's parent”. Moreover, five groups of students (total 290 students) from five primary schools were settings for discussion regarding dengue knowledge and prevention skills. Participation by the students showed knowledge and dengue prevention guidelines in school and their households. Consensus of teachers' discussion and students' meeting indicated that dengue had been a big problem, and needed to be solved. The details of these results have been reported in a previous report as the first part of the study results.

\subsubsection{Participatory Program Development Step}

This step followed the consensus of all stakeholders reached at the meeting in the assessment step. These results indicated that the high risk of dengue in primary schools was from both primary school and their householders [20]. Data feedback to the school involved discussion with the primary schools using the results from the preparation and exploration step. The meetings were structured as a series of workshops attended by the researcher, and the teachers who were involved in dengue prevention and control in each primary school. The contents of the feedback data were integrated into the school-based education program. An education program [12] [13] [25] was used as a guide to develop this education program and enhance dengue prevention and control, in the primary school. The final draft of the education program was approved by all teachers in the school and representatives from community.

\subsubsection{Implementation Step}

The participatory education program in the primary school involved engaging together in activities between the student, teacher, and the student's family. Meeting once a month, activities included training skills for larval indices survey after teaching basic dengue knowledge. The researcher, health teacher, classroom teacher, and local health provider jointly participated in conducting the program in each primary school. A manual of basic knowledge concerning dengue prevention and control was explained to the students, during discussions, games, reward activities, and demonstrations with return demonstrations. A CAI of basic knowledge for dengue prevention and control was provided by the health and classroom teacher once a month. Teachers encouraged student to set up a fish bank and herbal garden in the school. Students were given a role to survey the larval index in both primary schools (inside and outside of school building), and their households (indoor and outdoor) such as: toilets; plant-related container; drinking water container, and discarded containers surrounding building and household.

Student's parents indirectly benefited from the education program receiving dengue knowledge from their children once a month. Students took the dengue manual to their home for sharing with family member, espe- 
cially their parent. Parents signed a consent form that they and their student were participating in the program. Moreover, dengue manual was signature to show that they had read the content in the manual. The program improved the students' abilities over three months. The large meetings of all the students were participatory and created several activities for dengue solutions from the beginning until the end of program.

\subsubsection{Evaluate Program or Re-Assessment Step}

The process and outcomes will encourage routine activities for dengue prevention and control in an Islamic school. The main activities of the step were the re-assessment step centred on assessing the outcomes. The step was a feedback step for the others steps such as the assessment, plan, implementation, and comparison before and after conducting the activities. The meetings were structured as a series of workshops attended by the researcher, and the teachers who were involved in dengue prevention and control in the school. Data collecting and analysis for the evaluation step used the same tools and methods as the assessment step.

\section{Results}

The study aimed to develop an education program in five primary schools. The results consisted of the basic knowledge of dengue prevention and control of students and their parents, larval indices in the primary school and the students' household, and morbidity rate of dengue during the study.

\subsection{The Participatory Program for Dengue Prevention and Control in Primary School}

The development of the education program was based on the capacity of the teachers, students, and the representative of the community. Different roles were devised based on their capacity. Teachers and students undertook all activities for the prevention and control of dengue. The researcher team's roles were to support, encourage, train, teach, and participate in all activities. The program consisted of activities and role of actions (Table 1).

Table 1. The participatory program and activities of health provider, teacher, student, and student's parent.

\begin{tabular}{|c|c|c|c|c|c|}
\hline \multirow{2}{*}{\multicolumn{2}{|c|}{ The participatory program for dengue prevention and control in primary school }} & \multicolumn{4}{|c|}{ Activities of all strakholders } \\
\hline & & \multirow{2}{*}{$\begin{array}{c}\text { Health } \\
\text { provider } \\
\sqrt{ }\end{array}$} & \multirow{2}{*}{$\begin{array}{c}\text { Health } \\
\text { teacher } \\
\sqrt{ }\end{array}$} & \multirow{2}{*}{$\begin{array}{l}\text { Student } \\
\qquad \sqrt{ }\end{array}$} & \multirow[t]{2}{*}{$\begin{array}{c}\text { Student's } \\
\text { parent }\end{array}$} \\
\hline 1. & $\begin{array}{l}\text { Knowledge training: Dengue’s basic knowledge } \\
\text { training for students once a month per school }\end{array}$ & & & & \\
\hline 2. & $\begin{array}{l}\text { Dengue manual; an manual for encouraging teacher } \\
\text { and student's parent to learn about dengue prevention and control }\end{array}$ & $\sqrt{ }$ & $\sqrt{ }$ & $\sqrt{ }$ & $\sqrt{ }$ \\
\hline 3. & $\begin{array}{l}\text { Computer Assisted Instructor (CAI), use animation } \\
\text { computer assistant instruction of basic knowledge } \\
\text { for dengue prevention and control by health and classroom teacher }\end{array}$ & $\sqrt{ }$ & $\sqrt{ }$ & $\sqrt{ }$ & \\
\hline 4. & $\begin{array}{l}\text { Testing: questionnaire for testing student's } \\
\text { knowledge of dengue prevention and control }\end{array}$ & $\sqrt{ }$ & $\sqrt{ }$ & $\sqrt{ }$ & \\
\hline 5. & $\begin{array}{l}\text { Dengue data: communication of the dengue situation } \\
\text { and incidence rate among school (teacher), health provider, } \\
\text { local administration organization, student and student's parent }\end{array}$ & $\sqrt{ }$ & $\sqrt{ }$ & $\sqrt{ }$ & $\sqrt{ }$ \\
\hline 6. & $\begin{array}{l}\text { Larval indices survey: larval indices survey and destroy mosquito } \\
\text { breeding sources inside the building and surrounding area of the } \\
\text { primary school and the student's household. Undertake activities } \\
\text { every seven days (a week) by student and send the fourth } \\
\text { week data to the health teacher once a month }\end{array}$ & $\sqrt{ }$ & $\sqrt{ }$ & $\sqrt{ }$ & $\sqrt{ }$ \\
\hline 7. & $\begin{array}{l}\text { Fish bank: putting fish for eating larvae into a large water container, } \\
\text { lotus basin, and water container in the bathroom two fish in a medium } \\
\text { size container, and several fish for a large size container or many larvae }\end{array}$ & & $\sqrt{ }$ & $\sqrt{ }$ & \\
\hline 8. & Herbal garden: primary school and household needed to expel mosquitoes & & $\sqrt{ }$ & $\sqrt{ }$ & \\
\hline 9. & $\begin{array}{l}\text { Larval indices program: the calculus computer program } \\
\text { which integrated community program } \\
\text { that address; http://www.dengue.wu.ac.th (Figure 1) }\end{array}$ & $\sqrt{ }$ & & & \\
\hline
\end{tabular}




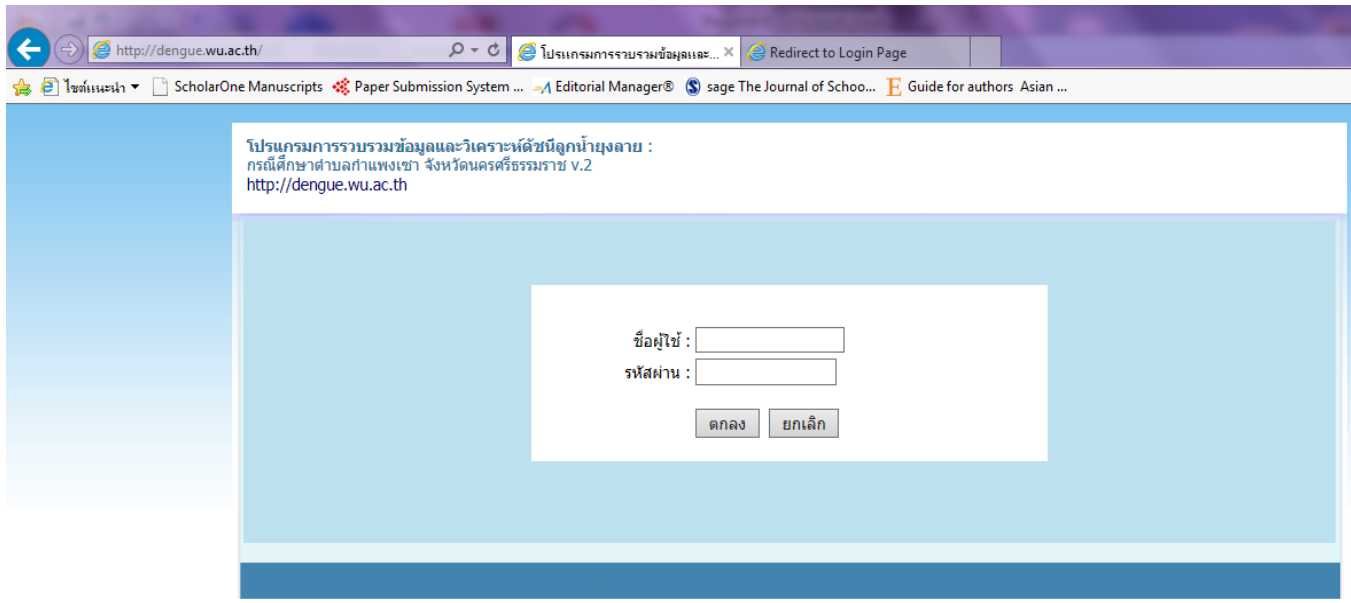

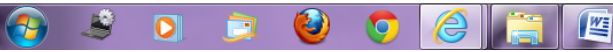

\section{บ้านของนักเรียนจำแนกรายโรงเรียน}

\section{ประจำเดือน มิฤนายน 2555}

\begin{tabular}{|l|c|c|c|}
\hline \multicolumn{1}{|c|}{ โรงเรียน } & BI & HI & CI \\
\hline โรงเรียนบ้านตาล & 515.63 & 78.13 & 28.30 \\
โรงเรียนบบานย่านชื่อ & $1,873.33$ & 93.33 & 40.49 \\
\hline โรงเรียนวัดชัน & 383.33 & 58.33 & 27.50 \\
\hline โรงเรียนวัดท้าวราษฎร์สงเคราะห์ & 492.13 & 74.02 & 27.06 \\
โรงเรียนวัดสวนพล & 506.67 & 83.33 & 33.70 \\
\hline
\end{tabular}

โรงเรียนวัดสวนพล

ตัชนีลุกน์ายงลายบำนของนักเรียน ประว่าเดือน บิฤุนายน 2555 วาแนกดามโรงเรียน

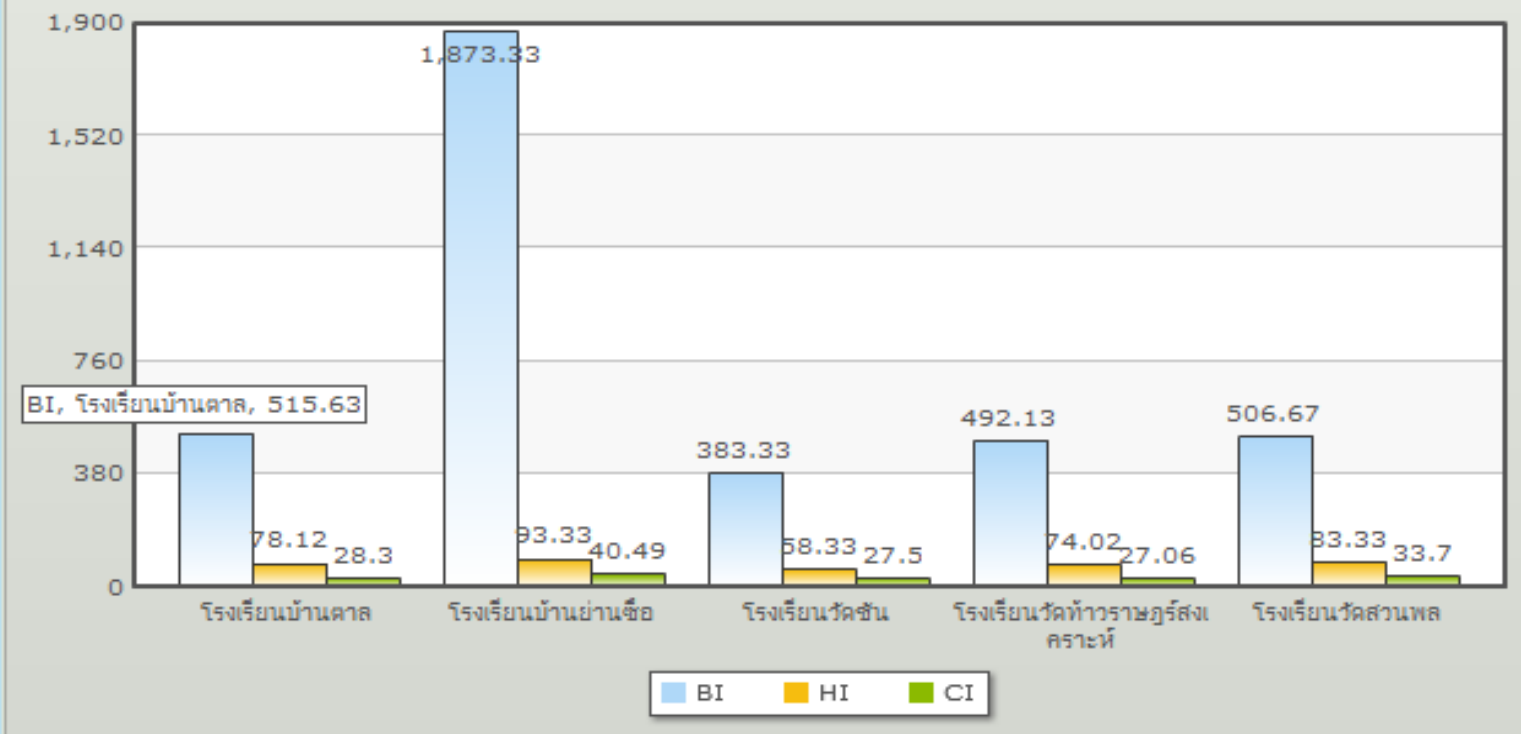

Figure 1. Larval indices program (http://www.dengue.wu.ac.th). 


\subsection{The Basic Knowledge for Dengue Prevention and Control of Students and Their Parents}

\subsubsection{Characteristics of Students and Their Parents}

The participatory program was used for three months with participation by all teachers, students, researchers, and the students' parents. There were 290 students and 242 of their parents in post-intervention. The 290 students were divided nearly equally into boys and girls (54.5\%, 45.5\%). Most of the students were 10 years old (33.8\%), their education level was basic primary education level four (36.6\%), dengue experiences were 15.9\%, and the most common occupation of their family was that of farmers (45.5\%). The characteristics between pre-intervention [20] and post-intervention (This study) are presented as demographic variables using the Chisquare $\left(\chi^{2}\right)$ test. They were not statistically significantly different for gender and education level $\left(\chi^{2}=0.136, P=\right.$ $\left.0.712 ; \chi^{2}=2.174, P=0.903\right)$ but age and family occupation were statistically significantly different $\left(\chi^{2}=5.989\right.$, $\left.P=0.05 ; \chi^{2}=16.863, P=0.01\right)$. The test was essential for the next tests of dengue basic knowledge pre- and post-intervention, since the demographic variables in the study could affect the output variable (Not shown the table).

\subsubsection{Dengue from Sources Information}

The post-intervention group included 290 students who evaluated the sources of information of dengue. They information sources were increasing score from pre-intervention and statistically significantly different $(P<$ 0.01, $P<0.001$, Table 2). This study showed that four sources of dengue information for students and their parents namely family, television, community dengue project, and other sources were not statistically significantly different. There were five information sources that were statistically significantly different $\left(\chi^{2}\right.$-test) namely information from the dome of community $(P<0.05)$; village health volunteer $(P<0.01)$; neighborhood, health provider, and the teacher at the school $(P<0.001)$ (Table 2).

\subsubsection{Dengue's Basic Knowledge of Student}

The 290 students who undertook the pre-intervention test in this study represented 94.77\% of the total target population of 306 students. There were 10 questions which more than $80 \%$ of students answered correctly including question $1 ; 2 ; 5 ; 9 ; 10 ; 11 ; 12 ; 13 ; 14$ and 15 (84.5\%; 85.5\%; 82.8\%; 89.0\%; 93.4\%; 81.4\%; 82.2\%; 86.2\%; $86.2 \%$ and $92.8 \%$ as following).

By comparing the pre and post-intervention of students group, there was an increasing level correctness with more than $80 \%$ answering correctly from 5 to 10 questions, respectively. Chi-squared $\left(\chi^{2}\right)$ statistical analysis showed that the answer in all questions at pre-intervention (Suwanbamrung, et al., 2013) and post-intervention which were highly statistically significantly different $(P<0.001)$ were questions $1,3,8,12,13$ and 15 . There were two items presenting lower statistically significantly different $(P<0.05)$ questions 5 and 11 . Almost seven questions were not significantly statistic different namely 2, 4, 6, 7, 9, 10, and 14 (Table 3).

Table 2. Sources of dengue information of post-intervention that received sources of dengue Information between students and their parents.

\begin{tabular}{|c|c|c|}
\hline \multirow{2}{*}{ Sources of dengue information } & \multicolumn{2}{|c|}{ Frequency (n) and Percentage (\%) } \\
\hline & Pre-intervention $(\mathrm{n}=306)$ & Post-intervention $(\mathrm{n}=290)$ \\
\hline Family $^{c}$ & $176(57.5)$ & 156 (53.8) \\
\hline Neighborhood $^{d}$ & $77(25.2)$ & $105(36.3)$ \\
\hline Village health volunteer $^{d}$ & $86(28.1)$ & $130(44.8)$ \\
\hline Health provider $^{d}$ & $49(16)$ & $83(28.6)$ \\
\hline Information dome of community $^{d}$ & $54(17.6)$ & $60(20.7)$ \\
\hline Television $^{d}$ & $224(73.2)$ & $183(63.1)$ \\
\hline Teacher at the school ${ }^{d}$ & 87 (28.4) & $71(24.5)$ \\
\hline Community dengue project $^{d}$ & $28(9.2)$ & $61(21.0)$ \\
\hline Other (hospital, radio, newspaper) $^{d}$ & $8(2.6)$ & $16(5.5)$ \\
\hline
\end{tabular}

Chi-squared $\left(\chi^{2}\right)$ statistic: ${ }^{a}$ non significant; ${ }^{b} P<0.05 ;{ }^{c} P<0.01 ;{ }^{d} P<0.001$. 
Table 3. The student’s basic knowledge of correct (\%) between pre and post-intervention.

\begin{tabular}{|c|c|c|}
\hline \multirow{2}{*}{ Dengue basic knowledge } & \multicolumn{2}{|c|}{ Corrected answer (\%) } \\
\hline & Pre-intervention & Post-intervention \\
\hline 1. Aedes aegypti is a conductor of dengue fever ${ }^{d}$ & $176(57.5)$ & $245(84.5)$ \\
\hline 2. A high risk of dengue fever will occur in all populations in the community ${ }^{a}$ & $252(82.5)$ & $248(85.5)$ \\
\hline 3. Aedes aegypti can fly from house to another house 50 - 100 meters away $^{d}$ & 113 (36.9) & 207 (71.4) \\
\hline 4.Very high and sustained fever $2-7$ days is usually a sign of dengue fever ${ }^{a}$ & $200(65.4)$ & $207(71.4)$ \\
\hline $\begin{array}{l}\text { 5. Dengue fever usually results in a red face and skin bleeding } \\
\text { (arm and leg) after a fever for } 2-3 \text { days }^{b}\end{array}$ & $229(74.8)$ & $240(82.8)$ \\
\hline $\begin{array}{l}\text { 6. Dengue treatment must follow only the signs and symptoms } \\
\text { because there is no specific drug }\end{array}$ & $105(34.3)$ & $133(45.9)$ \\
\hline 7. Patients with dengue fever may die ${ }^{a}$ & $222(72.5)$ & $228(78.6)$ \\
\hline 8. Aedes aegypti habitually bite in the day time ${ }^{d}$ & $65(21.2)$ & $147(50.7)$ \\
\hline $\begin{array}{l}\text { 9. Aedes aegypti like breeding in water containers which are clean } \\
\text { such as water containers in the bathroom and water jars }{ }^{a}\end{array}$ & $258(84.3)$ & $258(89.0)$ \\
\hline $\begin{array}{l}\text { 10. Coconut shells, broken water jars, and garbage with stagnated } \\
\text { water surrounding the household are Aedes aegypti breeding sources }{ }^{a}\end{array}$ & $273(89.2)$ & $271(93.4)$ \\
\hline 11. Closed water jars and water containers are a method to prevent mosquito breeding ${ }^{b}$ & $217(70.9)$ & $236(81.4)$ \\
\hline $\begin{array}{l}\text { 12. Eliminate mosquito breeding sources with clean } \\
\text { container and change the water every } 7 \text { days }^{d}\end{array}$ & $206(67.3)$ & $240(82.2)$ \\
\hline 13. Dry red lime can be in water container to decrease mosquito breeding ${ }^{d}$ & $128(41.8)$ & $250(86.2)$ \\
\hline 14. Sleep in a net to prevent mosquito bites ${ }^{a}$ & $290(95.8)$ & $275(86.2)$ \\
\hline 15. Citronella is herb for expelling mosquito ${ }^{d}$ & $252(82.4)$ & $269(92.8)$ \\
\hline
\end{tabular}

Chi-squared $\left(\chi^{2}\right)$ statistic: ${ }^{a}$ non significant; ${ }^{b} P<0.05 ;{ }^{c} P<0.01 ;{ }^{d} P<0.001$.

\subsection{Larval Indices Survey}

\subsubsection{Larval Indices of Five Primary Schools and Students' Households}

Larval surveys were conducted to determine types of containers and larval indices in the five primary schools and students' households. The survey of pre-intervention was conducted on June, 2012 (305 households), and conducted as part of the education program activities every months (September-November, 2012). The post-intervention surveys were done during December, 2012 showed larval indices rate (\%) of five primary school and their households (275 households). The total BI, HI, and CI ratio (\%) in the five primary schools pre and post-intervention in the community were 200,60 , and 8 , and increased to 220, 60, and 10 at post-intervention. In detail, the two schools didn't found any positive containers (BI, HI, and CI; 0:0: and 0). In contrast, their households' survey showed a decreasing ratio of BI, HI, and CI from pre-test (754, 77, and 35) to post-test (616, 81, and 32) (Table 4).

\subsubsection{Type of Water Container between Pre- and Post-Intervention}

There were seven types of water container inspected from the larval survey during the pre-intervention (June, 2012) and post-intervention (December, 2012). The number of inspected positive containers as a percentage of the containers inspected of the five primary schools in pre- and post-intervention decreased from 126:10:8 to 93:9:10. In terms of the type of water container, "water containers in the bathroom and toilet" ratio was high, and "Cupboard saucers" ratio was zero in both pre- and post-intervention. "Water containers in the bathroom and toilet", "Discarded containers were surrounding the household", and "Plants-related containers" showed a high percentage of positive containers. The students' households' survey found the number of positive containers as a percentage of containers inspected pre- and post-intervention (306 and 290 households) increased from 4013: 1407: 35 to 4486: 1574: 35. In types of water container, "Discarded containers were surrounding the household" in pre- and post-intervention were found to display a high percentage of positive containers per container inspected because the rainy season (Table 5). 
Table 4. Percentage of larval indices (\%) between pre- and post-intervention of primary schools.

\begin{tabular}{|c|c|c|c|c|}
\hline \multirow{3}{*}{$\begin{array}{l}\text { Larval indices ratio } \\
\text { (Percentage) }\end{array}$} & \multicolumn{4}{|c|}{ Percentage of larval indices (\%) } \\
\hline & \multicolumn{2}{|c|}{ Five primary schools } & \multicolumn{2}{|c|}{ Students' households } \\
\hline & Pre $(n=5)$ & Post* $(n=5)$ & Pre $(n=305)$ & Post $(n=275)$ \\
\hline $\begin{array}{l}\text {-The number of positive containers per } \\
100 \text { houses inspected: } \mathrm{BI}(\mathrm{BI}<50)\end{array}$ & 200 & 220 & 754 & 616 \\
\hline $\begin{array}{l}\text {-Percentage of houses infested with larvae and/or pupae; } \\
\text { the House Index: } \mathrm{HI}(\mathrm{HI}<10)\end{array}$ & 60 & 60 & 77 & 81 \\
\hline $\begin{array}{l}\text {-Percentage of water-holding containers infested } \\
\text { with larvae and/or pupae: CI }(\mathrm{CI}<1)\end{array}$ & 8 & 10 & 35 & 32 \\
\hline
\end{tabular}

*Three larval indexes were $0 \%$ in two of five primary schools.

Table 5. Types of containers, number of inspected, positive containers, and percentage of positive containers per container inspected pre- and post-intervention.

\begin{tabular}{|c|c|c|c|c|}
\hline \multirow{3}{*}{ Types of water containers } & \multicolumn{4}{|c|}{$\begin{array}{l}\text { Number of inspected: positive containers: percentage } \\
\text { of positive containers per container inspected (n: \%) }\end{array}$} \\
\hline & \multicolumn{2}{|c|}{ Five primary school } & \multicolumn{2}{|c|}{ Students' households } \\
\hline & Pre $(n=5)$ & Post $(\mathrm{n}=5)$ & Pre $(n=302)$ & Post $(\mathrm{n}=290)$ \\
\hline 1. Drinking water containers & 25:0:0 & 4:0:0 & $525: 51: 10$ & 694:145:21 \\
\hline 2. Water containers in the bathroom and toilet & $52: 4: 8$ & $68: 6: 9$ & 557:93:17 & $600: 152: 25$ \\
\hline 3. Used water containers & 7:0:0 & 8:0:0 & 630:93:17 & 671:212:32 \\
\hline 4. Cupboard saucers & 0:0:0 & 0:0:0 & 314:58:18 & $562: 217: 39$ \\
\hline 5. Vases & $4: 1: 25$ & 0:0:0 & $185: 43: 23$ & 371:128:35 \\
\hline 6. Plants-related containers & 18:1:6 & $2: 1: 50$ & 442:127:29 & 438:187:43 \\
\hline 7. Discarded containers surrounding the household & 20:4:20 & $11: 2: 18$ & 1360:860:63 & 1150:533:46 \\
\hline Total & 126:10:8 & 93:9:10 & 4013:1407:35 & 4486:1574:35 \\
\hline
\end{tabular}

\subsection{Dengue Morbidity Rate}

Dengue morbidity rate was the epidemiological index in study of dengue prevention program. This study, the data was monitored and collected from the local health promotion hospital of the study's setting. The comparison of morbidity rate of dengue from the start of the study to using education program (April-September, 2012) was 45 per 100,000 people, but during and post-intervention (September-November, 2012) there wasn't any morbidity rate presenting in the community.

\subsection{Feedback of All Stakeholders}

A final meeting was set for feedback concerning the study's results, and concluded that the program should continue. The 20 participants as representatives of stakeholders i.e. the school, health provider, community leader, teacher, school director, and local administrative organization discussed and confirmed that the education program would be used as a routine program in the primary school. The conclusion confirmed the effectiveness of the education program. Their opinions included "my school's policy supports all activities of the dengue program, I will teach students every Friday" a health teacher; the director of a small primary school said "I shall support both classroom and health teachers for training/teaching the knowledge and skills for dengue prevention". Moreover, a health provider and two deputies of the local administrative organization confirmed their strong supporting for them [23].

From students meeting in each school, the students concluded that the program help them from dengue risk. They understood the survey format, time for survey, step of report of survey to the assigned classroom teacher, 
and health teacher. Their words pointed such as “...understating larval indices in my school and my house... mosquito is risk for dengue" "dengue makes human death... I think student must be surveying their household...” "...the activities... need classroom teacher help student”

\section{Discussion}

Students in the study were all students at primary level 4, 5, and 6 in five primary schools, and all students had their parents' consent. The pre- and post-intervention groups were not different significantly in gender or education level, but were statistically significantly different in age and family occupation. The pre- and post-intervention study started April to December, 2012 (nine months), and covered two semesters and thus one educational year. There were 290 students (94.7\%) post-intervention who increased their basic knowledge of dengue prevention and control from 306 students (100\%) pre-intervention. The post-intervention test was 16 students lost because some student had task with their family. However, their characteristics were not statistically significantly different for gender and education level. In the post-intervention test an increase in the correct answers was found. Specifically, the number of correct items increased to more than $80 \%$ from five to 10 items pre- and post-intervention, respectively with 242 students' parents providing the correct answer (11 items). Moreover, post-intervention of students and their parent were significantly different for nine questions, and not different for six items. This might be explained by the increase in dengue information during the program. Both groups had increased information sources such as: teachers; the dengue project and health provider. The research team explained knowledge of dengue based on the questions for example, "Citronella is herb for expelling mosquito" and "Dry red lime can be in water container to decrease mosquito breeding". Moreover, question 13 "Dry red lime can be in water container to decrease mosquito breeding” revealed a higher percentage of students (86.2\%) who answered it correctly compared to their parents (78.9\%). These results confirmed the effects of the education program which increased dengue knowledge of students and in some cases their parents [10]-[13] [25].

Three larval indexes showed high levels in pre-intervention both at the primary school and students' households [20], and didn't match with the Thai Ministry of Public Health, and WHO [23] [24]. The high density of larval indices has been found in other studies of larval indices in Thailand [26] [27]. Although, post-intervention, the five primary schools showed a total decrease in the BI, and HI levels, but an increasing CI. Two primary schools didn't find any infested containers because both schools were smaller than the others. This might be valuable for management teachers and students. The schools director, classroom teacher, and health teacher participated wholeheartedly with the education program. These results show it is important to have the teacher's commitment for successful dengue solutions in schools [11] [12]. Focusing on the larval indices of students' households (BI, HI, and CI) these were high and an increasing number of containers were infected post-intervention. As in a previous study, high larval indices followed the season, wet or dry in Thailand. This study showed high level of indexes of the first survey pre-intervention in June, 2012, and post-intervention in December, 2012. Generally, Thailand has two different seasons, wet and dry. The wet season commonly runs from June to November, and the dry season from November to May. The peak dengue outbreak in Thailand generally occurs during the rainy period (July-September) when the mosquito population begins to expand [27]. These factors led to an increase in all larval indices at students' households post-intervention as September to November is the rainy season [3] [28] an important factor of several factors that affect the epidemic of dengue [29]. Moreover, the students' households had a greater number of indoor breeding habitats such as drinking water containers, water containers in the bathroom and toilet, and used water containers. Many discarded containers surrounding the household and plant-related containers were found, greater than other types of containers outdoors. By comparing pre- and post-intervention, the number of positive water containers in the students' households increased. These results related to the rainy season because students' parents collected water for use in their houses. These results were associated with the parent's belief and dengue knowledge understanding which needed to be directly communicated through the dengue education program. Most students' parents were female (77.3\%), data showed women were important for encouraging students who participated in the dengue education program. Women were more concerned than men about dengue prevention and control [30].

Although the study did not show a morbidity rate during the program, the risk of a dengue outbreak is high because both primary schools and students' households had high levels of larval indices. Moreover, the early phase of this study showed a morbidity rate (45 cases/100,000 population). These signs predict a risk of dengue transmission [26] [31] [32]. It follows that the health teacher, classroom teacher, school director must continue 
the program. The school director, classroom teacher, health teacher, and parents are all important in achieving this [12]. The school director where no infestation was found said that "the meeting students' parents for dengue prevention and control at least once per semester, such as in the first day of the semester, using a CAI usually every Friday”. These remarks suggest the results of this program will enable awareness of the dengue problem.

Only a participatory education program in primary school will not be completely effective in reducing the dengue problem of school and student's households in the community. This program needs to be combined with the obvious conduction of community program form students' parents [33]. Moreover, the program needs continuous process more than three months as the routine activities in primary school and combination skill for survey and eliminate larval sources of students, teachers, and student's parents.

\section{Conclusion}

The study was conducting in five primary schools in a sub-district in southern regional Thailand. It's was to develop and evaluate an education program for dengue prevention and control in five primary schools, using schoolbased participatory action research. There were five steps: 1) preparation teacher and school; 2) assessment the environment, larval indices survey; 3) education program development based on the context of school; 4) implementation the program; and 5) monitoring and evaluation. The results showed the participatory program consisted of nine important activities for all stakeholders involving dengue problem. Health teacher's activities and student's activities were eight activities consisted of knowledge training, dengue manual, CAI, test, dengue data, larval indices survey, fish bank, and herbal garden. The seven activities were the role of health provider which were knowledge training, dengue manual, CAI, testing, dengue data, larval indices survey, and larval indices program. Three activities were the important role of students' parents which included dengue manual, dengue data, and larval indices survey. The 290 students were participating activities in education program and increasing basic knowledge of dengue prevention and control. Student's dengue knowledge was increasing the correcting items and two primary schools were continuing non-positive containers (Container Index: $\mathrm{CI}=0$ ). However, the total larval indices (Breteau Index: BI, House Index: HI, and Container Index: $\mathrm{CI}$ ) of five primary schools showed high levels both pre- and post-intervention in primary schools. Moreover, the students' households showed high level of BI, HI and CI both pre- and post-intervention (754, 77, and 35 to 616, 81, and 32). Then, the program was needed to continue in primary school and participate from health teacher, health provider, and students' parents in order to be of great benefit for students.

\section{Acknowledgements}

Grateful acknowledgements are to all participants such as student in five primary schools, teachers, and representatives of the communities surrounding the primary schools. The author(s) would like to thank Health Fund of Kamphaeng Sao, Institute of Research and Development, Walailak University, and the School of Nursing for support in providing available time. Moreover, I am special thanks to Asst. Prof. Dr. David J. Harding who edits the manuscript.

\section{References}

[1] Guzman, M.G., Halstead, S.B., Artsob, H., Buchy, P., Farrar, J, Gubler, D.J., Hunsperger, E., et al. (2010) Dengue: A Continuing Global Threat. Microbiology, S7-S16. http://dx.doi.org/10.1038/nrmicro2460

[2] Thai Ministry of Public Health (2011) Reported Dengue Fever and Dengue Hemorrhagic Fever Situation. http://dhf.ddc.moph.go.th/status.htm

[3] Promprou, S., Jaroensutasinee, M. and Jaroensutasinee, K. (2005) Climatic Factors Affecting Dengue Heamorrhagic Fever Incidence in Southern Thailand. Dengue Bulletin, 29, 41-48.

[4] Arunachalam, N., Tana, S., Espino, F., Kittayapong, P., Abeyewickreme, W., Wai, K.T., et al. (2010) Eco-Bio-Social Determinants of Dengue Vectoe Breeding: A Multicounty Study in Urban and Periurban Asia. Bulletin of the World Health Organisation, 88, 173-184. http://dx.doi.org/10.2471/BLT.09.067892

[5] Constantinnus, J.M.K., et al. (2006) Dengue Knowladge and Practices and Their Impact on Aedes aegypti Populations in Kamphaeng Phat, Thailand. The American Journal of Tropical Medicine and Hygiene, 74, 693-700.

[6] Spiegel, J.M., Bonet, M., Ibarra, A.-M., Pagliccia, N., Ouellette, V. and Yassi, A. (2007) Social and Environmental Determinants of Aedes aegypti Infestation in Central Havana: Results of a Case-Control Study Nested in an Intergrated Dengue Surveillance Programe in Cuba. Tropical Medicine and International Health, 12, 503-510. 
http://dx.doi.org/10.1111/j.1365-3156.2007.01818.x

[7] Kittayapong, P, Chansang, U., Chansang, C. and Bhumiratana, A. (2006) Community Participation and Appropriate Technologies for Dengue Vector Control at Tranmission Foci in Thailand. Journal American Mosqito Control Association, 22, 538-546. http://dx.doi.org/10.2987/8756-971X(2006)22[538:CPAATF]2.0.CO;2

[8] Al-Muhandis, N and Hunter, P.R. (2011) The Value of Educational Massages Embedded in a Community-Based Approach to Dengue Fever: A Systematic Review and Meta Regression Analysis. PLoS Neglected Tropical Diseases, 5, $1-9$.

[9] Focks, D.A. (2004) A Review of Entomological Sampling Methods and Indicates for Dengue Vectors. WHO (WHO/ TDR/IDRDen.03.1), Geneva.

[10] Winch, P.J., Leontsini, E., Rigau-Pérez, J.G., Ruiz-Pérez, M., Clark, G.G. and Gubler, D.J. (2002) Community-Based Dengue Prevention Programes in Puerto Rico: Impact on Knowledge, Behavior, and Residential Mosquito Infestation. The American Society of Tropical Medicine and Hygiene, 67, 363-370.

[11] Srisawad, T., et al. (2008) The Effectiveness of Aedes aegypti Laral Control and DHF Incidence in Pre-Epidemic Period. Vector Borne Disease Journal, 5, 14-23.

[12] Khun, S. and Manderson, L. (2007) Community and School-Based Health Education for Dengue Dontrol in Rural Cambudia: A Process Evaluation. PLoS Neglected Tropical Diseases, 1, 1-10. http://dx.doi.org/10.1371/journal.pntd.0000143

[13] LaBeaud, A.D., Glinka, A., Kippes, C. and King, C.H. (2009) School-Based Health Promotion for Mosquito-Borne Disease Prevention. The Journal of Pediatrics, 155, 590-592. http://dx.doi.org/10.1016/j.jpeds.2009.03.009

[14] Suwanbamrung, C., Tapalak, N., Jitchun, C., Promsuwan, C., Prosupa, S., Muenraj, Y. and Dumpan, A. (2012) Student Capacity Building of Dengue Prevention and Control: A Study of an Islamic School, Southern Thailand. Health, 4, 366-379. http://dx.doi.org/10.4236/health.2012.47059

[15] Avila Montes, G.A., Martínez, M., Sherman, C. and Fernández Cerna, E. (2004) Evaluation of an Educational Module on Dengue and Aedes aegypti for Schoolchildren in Honduras. The Pan American Journal of Public Health, 16, 84-94.

[16] Lennon, J. (2004) Students' Perceptions about Mosquito Laval Control in a Dengue-Endemic Philippine City. Dengue Bulletin, 28, 196-206.

[17] Madeira, N.G., Macharelli, C.A., Pedras, J.F. and Delfino, M.C.N. (2002) Education in Primary School as a Strategy to Control Dengue. Evista da Sociedade Brasileira de Medicine Tropical, 35, 221-226. http://dx.doi.org/10.1590/S0037-86822002000300004

[18] Tampon Yan Sou District Health Promotion (2012) Dengue/Dengue Heamorrhagic Fever Statistic. Kumpeang Sou District Nakhon Si Thammarat Province.

[19] Suwanbamrung, C., Dumpan, A., Thammapalo, S., Sumrongtong, R. and Phedkeang, P. (2011) A Model of Community Capacity Building for Sustainable Dengue Problem Solution in Southern Thailand. Health, 3, 584-601. http://dx.doi.org/10.4236/health.2011.39100

[20] Suwanbamrung, C., Promsupa, S., Doungsin, T. and Tongjan, S. (2013) Risk Factors Related to Student Dengue Problems in Primary School: Exploring Dengue's Basic Knowledge and Larval Indices. Southern Thailand. Journal of Infection and Public Health, 6, 347-357. http://dx.doi.org/10.1016/j.jiph.2013.04.006

[21] Gibbon, M.R., Labonte, R. and Laverack, G. (2002) Evaluation Community Capacity. Health and Social Care in the Community, 10, 485-491. http://dx.doi.org/10.1046/j.1365-2524.2002.00388.x

[22] Toledo, M.E., Vanlerberghe, V., Perez, D., Lefevre, P., Ceballos, E., Bandera, D., Gil, A.B. and Van der Stuyft, P. (2007) Achieving Sustainability of Community-Based Dengue Control in Santiago de Cuba. Social Science \& Medicine, 64, 976-988. http://dx.doi.org/10.1016/j.socscimed.2006.10.033

[23] WHO (1999) Prevention and Control of Dengue and Dengue Hemorrhagic Fever: Comprehensive Guidelines. WHO Regional Publication, New Delhi, SEARO No. 29.

[24] WHO(1993) Monograph on Dengue/Dengue Haemorrhagic Fever. Regional Office for South-East Asia, New Delhi.

[25] Suwanbamrung, C. (2012) Children’s Basic Knowledge and Activities for Dengue Problem Solution: An Islamic Religious School, Southern, Thailand. Asia Pacific Journal of Tropical Disease, 2, 456-464. http://dx.doi.org/10.1016/S2222-1808(12)60100-5

[26] Thammapalo, S., Nagao, Y., Sakamoto, W., Saengtharatip, S., Tsujitani, M., Nakamura, Y., Coleman, P.G. and Davies, C. (2008) Relationship betaween Transamission Indensity and Incidence of Dengue Heamorrhagic Fever in Thailand. PLoS Neglected Tropical Diseases, 2, 1-13. http://dx.doi.org/10.1371/journal.pntd.0000263

[27] Chareonviyaphap, T., et al. (2003) Laval Habitants and Distribution Paterns of Aedes Aegypti (Linnaeus) and Aedes Alopictus, in Thailand. Southeast Asian Journal of Tropical Medicine and Public Health, 34, 7.

[28] Bar, A. and Andrew, J. (2012) Seasonal Prevalence of Aedes aegypti Larval in Agra. Research in Zoology, 2, 4. 
[29] Torres, J.R. and Castro, J. (2007) The Health and Economic Impact of Dengue in Latin America. Cadernos de Saúde Pública, 23, S23-S31. http://dx.doi.org/10.1590/s0102-311x2007001300004

[30] P'erez-Guerre, C.L., Zielinski-Gutierrez, E., Vargas-Torres, D. and Clark, G.G. (2009) Community Belivefs and Practices about Dengue in Puerto Rico. Revista Panamericana de Salud Pública/The Pan American Journal of Public Health, 25, 9.

[31] Sanchez, L., Cortinas, J., Pelaez, O., Gutierrez, H., Concepción, D. and Van der Stuyft, P. (2010) Breteau Index Threshold Levels Indicating Risk for Dengue Tranmission in Areas with Low Aedes Infestion. Tropical Medicine and International Health, 15, 3. http://dx.doi.org/10.1111/j.1365-3156.2009.02437.x

[32] Sanchez, L., Vanlerberghe, V., Alfonso, L., del Carmen Marquetti, M., Guzman, M.G., Bisset, J. and van der Stuyft, P. (2006) Aedes aegypti Larval Indicies and Risk for Dengue Epidemics. Emerging Infectious Diseases Journal, 12, 800 806. http://dx.doi.org/10.3201/eid1205.050866

[33] Erlanger, T.E., Keiser, J. and Utzinger, J. (2008) Effect of Dengue Vector Control Interventions on Entomological Parameters in Developing Countries: A Systematic Review and Metalysis. Medical and Veterinary Entomology, 22, 203-221. http://dx.doi.org/10.1111/j.1365-2915.2008.00740.x 